\title{
THE IMPACT FACTORS ON PROJECT MANAGEMENT SUCCESS IN GLOBAL TEAMS: THE CASE OF COMPANY "X" PROJECTS
}

\author{
Inese Sluka ${ }^{1}$, Sintija Kristine Brence ${ }^{2}$
}

\begin{abstract}
Nowadays, with globalization and the development of information technology, global teams are one of the fastest growing types of teams. Communication technology capabilities have significantly reduced the cost of team management and remote collaboration. Current management science has a broad theoretical basis for managing teams that are physically located in one place, but there is much less understanding of how leaders can effectively manage global teams.

Company $\mathrm{X}$ is a global management consulting, technology services and outsourcing company. All company projects have virtual teams and participants from different countries

The goal of this research is to identify and study the factors that influence the success of global project team management and operations in Company X.

The research provides answers to the following questions: 1) Which factors impact the project management success at global company X?; 2) What is the impact of a team member's role and experience on project management success at company X?; 3) What are the cultural differences within the project teams?

The data was collected from a survey of two global teams $(n=31)$ at global company X. Team members represent three cultures: Finnish, Indian and Latvian. The analyzed factors were communication, remote communication tools, roles and rules, and trust and cooperation in a multicultural environment. Communication, remote communication tools, and roles and rules showed a statistically significant impact on project management success in global teams. The current role of team members has a negative effect on project management success.
\end{abstract}

No statistically significant differences between cultures were found which supports Cultural Convergence Theory which suggests that two cultures will be more and more like each other as their interactions increase.

JEL Classification Numbers: M14, DOI: https://doi.org/10.12955/peb.v1.29

Keywords: global team, project management success, culture differences

\section{Introduction}

Researching global teams often overlaps with researching multi-national, multi-cultural, virtual and remote teams. Research studies into multi-national and multi-cultural teams strives to mark out intercultural interaction, whereas studies into virtual and remote teams strives to emphasise the interaction of the participants in time and space. All of these factors are essential in the context of global teams because they are both multi-national / multi-cultural and virtual/ remote, as they cover several countries, cultures, geographical locations and time zones (Gibbs \& Boyraz, 2015).

Company $\mathrm{X}$ is a global company that manages projects and provides technology service consultancy in more than 120 countries. The goal of the research is to identify and study the factors that influence the success of global project team management in Company X. Global companies have to deal with the necessity to support project management teams with clearly defined rules and roles for the team members who are in different locations. Company X expands their operations for labour force availability and optimisation purposes, thus ensuring that, for instance, project teams may work continually in various time zones. Also, a challenge for the project manager is to build trust, communication and collaboration in the project team, and deal with cultural differences to reach the project goal. The project managers in Company X faced different problems in their project teams which in their opinion are based on cultural differences. An analysis of the literature reveals a much broader view of the impact factors on project management success in global teams. This research study analyzed two global teams in Company $\mathrm{X}$ to develop recommendations for the project managers to improve project success.

\section{Project Management Success Factors in Global Teams}

Generally, global teams differ from other teams in two ways: 1) globally scattered working environment and 2) heterogeneity / differences on several dimensions (such as nationality, culture, sex, age etc.) (Malloney \& Zellmer-Bruhn, 2006). Global teams feature national, cultural and language diversity. They operate across space, time, cultures and the borders of the organisation, in a globally scattered virtual environment (Zander et al., 2012). Global teams operate mainly using electronic communication (Prasad, Akhilesh, 2002; Zander et al., 2012).

\footnotetext{
${ }^{1}$ RISEBA University of Applied Sciences, Riga, Latvia, inese.sluka@ riseba.lv

${ }^{2}$ RISEBA University of Applied Sciences, Riga, Latvia, sintija.brence@ outlook.com
} 
Project success is one of the most scientifically researched topics in project management. Project success consisting of two components: project management success and product success (Sudhakar, 2012). This research field is limited to project management success. Critical project management success factors in IT projects are clear project goals, a project schedule, planning and control mechanisms and project manager's competence (Sudhakar, 2012). In virtual teams, project success largely depends on the management skills of the team leader and their team, including conducting meetings, taking opinions, making decisions and knowing cultural differences (Alsnour, 2014; Presbitero, 2019). In various cultures, project management success is primarily influenced by the aim of the project, the scope and the communication within the team (Ludviga \& Sluka, 2018).

Communication with team, customers and other stakeholders is a key for project outcome (Naqvi, 2011). Isolation, maintaining or losing trust, communication, misunderstanding and suspicion are the key challenges in remotely operating teams, and project management is to be able to manage and motivate teams (Pollitt, 2006).

\section{Communication}

By carrying out a situational analysis, Baumöl and Großer (2017) found that the most important factor that affects the performance of virtual teams is communication routines. Feedback not only about work, but social events are also important. Malhotra et al. (2007) emphasise that it is critically important to build social relationships and common working and communication standards in intercultural teams. If there are no concrete communication standards, then team members choose for the practices which are the most widespread in the respective environment or for the practices they are most accustomed to (Malhotra et al., 2007).

Break (2006) suggests taking into account language competence and communicating clearly, and by giving examples for comprehension, encouraging the team members to ask questions and request further details as well as to give feedback regarding the ideas of the participants in order to improve communication in the virtual environment. Paul et al. (2016) suggest meeting in person at least once, but, in the event that that is not possible, then the assurance of social communication is critical.

Virtual communication, which purely relies on computerised communication technologies, is usually short of verbal means of expression, and this makes communication particularly complicated (Wei et al., 2018). The levels of the working language competence vary in global teams, and these differences increase the social distance (Neelay, 2015).

\section{Remote Communication Tools}

Technologies have an impact on business and on how teams work together (Prasad \& Akhilesh, 2002). Failure to understand each other in remote multicultural teams is affected by the different levels of the use of information technologies in various countries (Alnsour, 2014).

Technological failures mean failure of the project for virtually working teams. The technological solutions must be appropriate, maintained as well as provide technical support (Ford et al., 2017; Paul et al., 2016). Zander et al. (2012) draws attention to the fact that global teams need to have access to electronic platforms, but, as soon as they cannot be accessed by all the team members (due to the Internet or poor usage skills, for example), it inhibits expectations and preferences in cultures.

Communication technology usage standards need to be described in virtual teams, i.e., how often and in what manner the current document versions are maintained, when documents are to be placed within the platform, when to comment, what the key milestones are, how to inform other members, what other communication tools are to be used (Malhotra et al., 2007; Paul et al., 2016).

\section{Roles and Rules}

Remote teams should establish rules which are applicable in the states where the team members are located (Alnsour, 2014). The establishment of common rules and standards facilitates team collaboration and mutual trust (Malhotra et al., 2007). It is indicated in other parts of the article that the establishment of rules is important both in communication matters and the use of technologies.

Team roles are shown in the organisational structure of the team. The research study by Sluka \& Ludviga (2017) shows that the structure of a virtual team has influence on the satisfaction with the work of the team. Monalisa et al. (2015) points out that the establishment of clear team roles and responsibilities is critical for team success. Accurately defined roles and duties as well as the structure of the collaboration between the team members facilitate the attainment of common goals. 
Another research study proves that the clarity of the roles has influence on global team satisfaction and project success. Some of the challenges in the definition of the roles include the definition of different duties in various countries and the breakdown of the project team roles based not on skills but on the availability of the member (Henderson et al., 2016).

\section{Trust}

Although the degree of virtuality may vary among different organisations and projects, building and maintaining trust is key for virtual team success and will become more and more critical because technological opportunities will increase the amount of virtually scattered teams (Ford et al., 2017). Several research studies have shown that trust unites the team and influences the performance of a virtual team, including the success of the project (Saafein \& Shaykhian, 2014; Paul et al., 2016; Wei et al., 2018). The building of trust in remote teams is based on the availability of communication technologies, transparency and the rules for their use (Ford et al., 2017; Malhotra et al., 2007). Building trust in a global virtual team is the starting point for further team collaboration. Team leaders should make maximum use of the online tools in order to ensure formal and informal communication, find ways of involving the global team members in the life of the organisation as well as consider opportunities for the implementation of various virtual games that facilitate team building (Wei et al., 2018).

\section{Collaboration in Multicultural Team}

Collaboration is a cornerstone of project success in an organisation. Collaboration is much more than merely working together. It is a way of thinking as to how to act in a diverse environment, simultaneously covering essential project management components, such as resources, timing etc. (Hamersly \& Land, 2015).

A study by Saafein \& Shaykhian (2014) shows the influence of unity and collaboration on the performance of virtual teams. It is important to detail the collaboration mechanisms not only because everyone should have a common understanding, but also because most commonly the members cannot work simultaneously due to time zone differences (Zander et al., 2012). Trust, collaboration and equality in remote teams are also facilitated by the fact that all "suffer" equally from working in a geographically dispersed world. For example, by establishing team rules and introducing routines, team leaders may vary the weekly audio conference times, so that everyone (at some point in the team life cycle) experiences a late night or early morning meeting (Malhotra et al., 2007).

The efficiency of virtual collaboration is influenced by the tools and the convenience of their use, as well as by the appropriateness of the project objectives (Zhang et al., 2018).

The working ethics, working habits and the level of skills differ largely in various cultures. It is important that the team is aware of cultural differences in order to know how to act in various situations and be able to evaluate them (Siegel \& Madni, 2019). Culture largely differs in the willingness to spread bad news. It is simply not done in some cultures, and, therefore, it is important to know what the representatives of various cultures there are in the team (Siegel \& Madni, 2019).

According to Hofstede's comparison between cultures based on six dimensions, Latvia and Finland generally have similar results than India, but there are also differences between the two European countries (Hofstede, 2019). The biggest difference between Latvia and Finland lies in the indulgence dimension - the extent to which people try to control their desires and impulses (Finland 57, India 26, Latvia 13) and long-term orientation - maintaining past links while addressing present and future challenges (Latvia 69, India 51, Finland 38). In other dimensions, the biggest differences are between India and European countries. For example, power distance which means that not all individuals are equal (India 77, Latvia 44 and Finland 33).

\section{Data and methodology}

This research applies a quantitative methodology and primary data is gathered through a structured questionnaire which consists of 56 questions. It includes demographic questions and open questions (15 questions) and 41 questions about impact factors in global teams based on the literature review. Impact factors are coded and each of them contains a different number of questions: (1) project management success - PVV (8 questions), (2) communication - COM (6 questions), (3) remote communication tools - IKT (7 questions), (4) team rules and roles - ROLL (8 questions), (5) trust - TR (7 questions), (6) cooperation in multicultural team - COLL (5 questions). 
Company $\mathrm{X}$ is a global management consulting, technology services and outsourcing company. It employs nearly 500,000 people, serving customers in more than 120 countries worldwide. Currently, more than 100 projects are being implemented in Latvia for clients from different countries of the world. All company teams work remotely, and team members come from different countries. All the teams are global project teams.

The company has its own certified project management system that includes descriptions of all project management processes. Project management system content helps to manage all the projects. Teams have access to document templates that only need adaptation to the needs of the clients and the specifics of the project. The system ensures equal access to the documents by the team members.

The sample of the research study is the teams of two projects, " $\mathrm{A}$ " and " $\mathrm{B}$ ":

- Project of team "A"

The aim of the team "A" project is to establish infrastructural support for the IT systems of a client. The project implementation period was from August 2016 until January 2023. The project budget was 25 million USD. The project was implemented in collaboration with 1 partner. The team consisted of 18 members from 3 countries - Latvia, Finland and India. There are the following roles within the team: project manager, head of service provision, manager of service provision, company architect, technicians, conformity / quality specialist.

- Project of team " $\mathrm{B}$ "

The aim of the team "B" project was the elimination of errors in the current SAP system, the implementation of service requests, and problem management and improvement of the system with new functions based on customer requests. Information about the project timing and budget is confidential. The project was implemented with 10 partners in 5 different countries. The team consisted of 25 members from 3 countries - Latvia, Finland and India. There were the following roles within the team: project managers, team leaders, senior and junior technical developers, senior and junior technical consultants

Both project teams consisting of the current members had not worked together previously. Individual team members had met personally, but the entire team together had not. The team members located in the same country or the same city usually worked together in the same building. All of the team members had previous experience in working remotely and in a multicultural environment.

The questionnaire for the project teams was conducted online in the company's system. Responses to the questionnaire were gathered from November 2019 to January 2020. 31 completed questionnaires were received. The responses were analysed using a structural Equation modelling approach and Smart-PLS software. A variance based structural equation modelling (PLS-SEM) technique was used to answer research question No.1 - Which factors impact the project management success at global company X? and question No.2 - what is the impact of a team member's role and experience on project management success at company $\mathrm{X}$ ?

This technique was chosen because it implies the features of multiple regressions and does not assume the normality of the data distribution. The statistical objective of PLS-SEM is to maximize the explained variance of endogenous latent constructs or dependent variables (Hair et al., 2011).

The answer to the question No.3 - What are the cultural differences within the project teams? - were found through difference tests.

\section{Results and discussion}

\section{Respondent data}

$26 \%$ of the respondents are female, $68 \%$ are male and $6 \%$ indicated that they did not want to reveal their gender. $48 \%$ of respondents are Latvians, $42 \%$ are Indians and $20 \%$ Finns. $13 \%$ of the participants are between 18 and 24 years of age, 55\% are between 25 and 34 years of age, 26\% are between 35 and 44 years of age, and $6 \%$ are above 45 years of age.

$13 \%$ of the participants have up to 1 year of work experience in global teams, 39\% have between 1 and 3 years, 16\% have between 4 and 6 years of experience, and 32\% have 6 and more years of experience. $19 \%$ of respondents are project or delivery managers and $81 \%$ technical subject matter experts.

Analysis of impact factors

First, the reliability of the data was verified by calculating the Cronbach's Alpha coefficient. Two items from the remote communication tools scale, three items from the communication scale, one item from the 
team rules and roles scale, two items from the trust scale and three items from the cooperation in multicultural team scale, after examination of the statements and their wording, were excluded from the model since their loadings were below the minimum threshold value. For the Cronbach's Alpha coefficient, see Table 1 .

A bootstrapping procedure was used to determine statistical significance. All loadings were statistically significant $(\mathrm{p}=0.000)$ as seen in Fig. 1 . The inner model presents path coefficients and $\mathrm{p}$ values in parentheses, the outer model show only $\mathrm{p}$ values of manifest variables indicating that all manifest variables are statistically significant.

Convergent Validity of the reflective constructs was examined with average communality or AVE (average variance extracted) which should be higher than 50\%. In the model, AVE scores were the following: COL 0.78; IKT 0.70; COM 0.53; PVV 0.56; ROLL 0.59 and TR 0.62. All the scores are well above 0.5 and thus are acceptable.

Composite Reliability is an estimate of the constructs' internal consistency and should be above the threshold level of 0.6. Composite Reliability scores of the model are the following: COL 0.86; IKT 0.88; COM 0.60; PVV 0.88; ROLL 0.88 and TR 0.84. Composite reliability scores are well above the minimums thus indicating sufficient reliability, see Table 1.

Collinearity statistics revealed that all values are less than 5 , thus indicating that collinearity is not a problem for the model.

\begin{tabular}{|c|c|c|c|}
\hline Scale & Cronbach's Alpha & Composite Reliability & Average Variance Extracted (AVE) \\
\hline COL & 0.862 & 0.913 & 0.78 \\
\hline IKT & 0.887 & 0.921 & 0.705 \\
\hline COM & 0.609 & 0.766 & 0.534 \\
\hline PVV & 0.889 & 0.911 & 0.566 \\
\hline ROLL & 0.881 & 0.91 & 0.596 \\
\hline TR & 0.848 & 0.893 & 0.628 \\
\hline
\end{tabular}

The outer model shows how correctly each construct is measured or how each set of indicators are related to their latent variable. The model is designed (see Figure 1) with the help of Smart PLS software and algorithms calculated. The dependent variable is project management success in global teams.

The primary evaluation criteria for SEM are $\mathrm{R}^{2}$ results. The $\mathrm{R}^{2}(\mathrm{PVV})=0.847$ thus the model has a substantial predicting capacity. For the model, see in Figure 1.

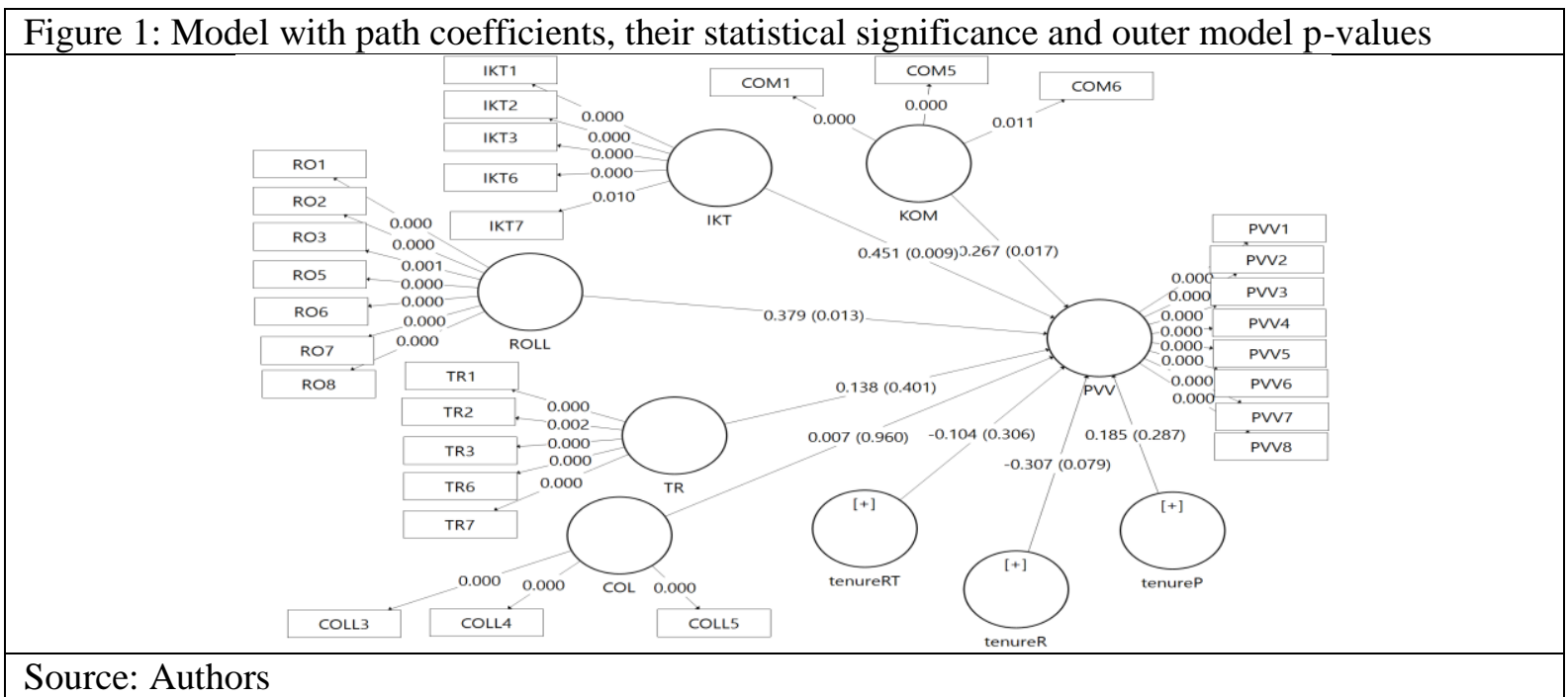

The individual paths coefficients of the PLS structural model are interpreted as standardised beta coefficients of OLS regressions (Hair et al., 2011). Data analysis reveals a strong relationship between IKT and PVV (path coefficient 0.45; $\mathrm{p}=.009$ ); COM and PVV (path coefficient 0.27; $\mathrm{p}=.017$ ) and ROLL and PVV (path coefficient 0.38; $\mathrm{p}=.013$ ). Other factors' (COL and TR) path coefficients are not 
significant. Thus, the model revealed that the strongest impact on project management success (PVV) had remote communication tools (IKT) and team rules and roles (ROLL), see Figure 1.

Jimenez et al. (2017) indicates that, until now, research of global virtual teams has been about studying cultural differences, communication channels and impacts of time zones, but little about the role of contemporary online tools. The results of this research study demonstrate the impact of the tools on the success of global team project management.

The significant impact of information communication tools on project management success can be explained by the fact that the working environment of the global project teams of the company $\mathrm{X}$ is the project management system created by the company. However, the respondents indicated that it was highly important to reach an agreement with the client at the start of the project about the tool to be used because, in the event of various systems, there are different approaches and data compatibility. The results of this research study are common with the results of other research studies. The study conducted by Saafein and Shaykhkian (2014) in telecommunication companies demonstrated that the performance of virtual teams impacts appropriate communication tools.

Communication is the second most essential factor that affects project success in the global projects of Company $\mathrm{X}$. The most common challenges specified by the respondents included the remote way of working, planning and the coordination of meeting times due to the busy schedules of the colleagues and time zone differences. The quality performance of the work is influenced by the fact that communication is too long because some colleagues delay their replies to e-mail messages or simply ignore them. Another challenge is the language barrier or the various English language accents.

The respondents specified in the open questions that open communication facilitates the building of trust. The roles and rules influence the project management success in Company X. Upon starting their work on the project, each member has a clear role, and there is a detailed description of the project objectives available. However, the responsibility may be increased, and additional duties may be added during the project. The accuracy of roles is also determined by the customer requirements which are or are not clearly defined. Any violations of the rules established by the team lower trust (Malhotra et al., 2007) and thus reduce the overall project success.

The success of the project in the following issues was analysed: 1) How long have you been working in this project? (Tenure P); 2) How long have you been in your current role? (Tenure R); 3) How long have you been working with international, remote project teams? (Tenure RT).

Data analysis shows that experience in remote project teams (path coefficient $=-0.104 ; \mathrm{p}<0.1$ ), and experience in this project (path coefficient $=0.185 ; \mathrm{p}<0.1$ ), has no effect on project success. Tenure in the current role has a negative effect on project management success (path coefficient $-0.3 ; \mathrm{p}<0.1$ ).

The longer a team member takes in the current role, the more negative effect it has on the project success. One of the role theory propositions explains that changing circumstances can make the social pressure to change a role. As mentioned before, the responsibilities of global team members can change and creates a desire to change a role. $42 \%$ of the participants wish to change their role in the project. A recommendation for the team leaders would be the develop an evaluation system when responsibilities are increasing.

The Kruskal-Wallis H-test was used to mutually compare more than two groups. There are no statistically significant age, sex or cultural differences between the two studied teams. Considering that the team employs members from 3 countries (Latvia, Finland and India), this result can be explained by the cultural convergence theory which stipulates that increased interaction between various cultures makes the cultures similar. In the teams of Company $\mathrm{X}$, this is facilitated by the availability of clear operating rules and a project management system.

\section{Conclusion}

In the operation of a global project team within a company with an orderly and clear internal environment, working standards understandable to everyone and clear roles, organised communication and availability of appropriate remote communication tools, the cultural differences create no disturbance during the course of the project. A global company which employs people from different cultures, nations and who work remotely at first should ensure availability of the same project management and communications tools for all team members. Also, they should provide training and technical equipment. The second recommendation for the Global companies to reduce the impact of cultural differences is to set clear rules 
and a clear project management process and to continuously improve upon them. A clear role description and explanation for the team members will ensure more successful global projects.

\section{References}

Alnsour, B. H. (2014). The use of virtual project teams for project management in Jordanian Corporations. Eurasian Journal of Business and Management, 2(2), 50-56. doi:10.15604/ejbm.2014.02.02.004

Brake, T. (2006). Leading global virtual teams. Industrial and Commercial Training,, 38(3), 116-121. doi:https://doi.org/10.1108/00197850610659364

Ford, R., Picollo, R., \& Ford, L. (2017). Strategies for building effective virtual teams: Trust is key. Business Horizons, 60(1), 25-34. doi:https://doi.org/10.1016/j.bushor.2016.08.009

Gibbs , J., \& Boyraz, M. (2015). International HRM's role in managing global teams. In D. Collings, G. Wood, \& P. Caligiuri (Eds.), The Routledge companion to international human resource management. Routledge.

Großer, B., \& Baumöl, U. (2017). Why virtual teams work - State of the art. Procedia Computer Science, 121, 297-305. doi:10.1016/j.procs.2017.11.041

Hair, J., Ringle, C., \& Sarstedt, M. (2011). PLS-sem: Indeed a silver bullet. The Journal of Marketing Theory and Practice, 19(2), 139-151. doi:10.2753/MTP1069-6679190202

Hamersly, B., \& Land, D. (2015). Building productivity in virtual teams. Revista de Gestao e Projetos - GeP. doi:10.5585/gep.v6i1.305

Henderson, L., Stackman, R., \& Lindekilde, R. (2016). The centrality of communication norm alignment, role clarity, and trust in global project teams. International Journal of Project Management, 34(8), 1717-1730.

doi:https://doi.org/10.1016/j.ijproman.2016.09.012

Hofstede, G. (2019). Hofstede Insights. Retrieved from Compare countries: https://www.hofstedeinsights.com/product/compare-countries/

Jimenez, A., Boehe, D., Taras, V., \& Caprar, D. (2017). Working Across Boundaries: Current and Future Perspectives on Global Virtual Teams. Journal of International Management, 341-349. doi:https://doi.org/10.1016/j.intman.2017.05.001

Ludviga, I., \& Sluka, I. (2018). Cultural Diversity in Project Management: How Project Success is Perceived in Different Cultures. Diversity in Organizations, Communities \& Nations, 18(1). doi:https://doi.org/10.18848/2328-6261/CGP/v18i01/1-12 Malhotra , A., Majchrzak, A., \& Rosen, B. (2007). Leading Virtual Teams. Academy of Management Perspectives, 21(1), 6070. doi:10.5465/AMP.2007.24286164

Malloney, M., \& Zellmer-Bruhn, M. (2006). Building bridges, windows and cultures: Mediating mechanisms between team heterogeneity and performance in global teams. Management International Review, 46(6), 697-720. doi:10.1007/s11575-0060123-5

Monalisa, M., Daim, T., Mirani, F., Dash, P., Khanis, R., \& Bhusuri, V. (2015). Managing global teams. Research Technology Management, 48-59. doi:https://doi.org/10.1080/08956308.2008.11657514

Naqvi, I. (2011). The impact of stakeholder communication on project outcome. African Journal of Business Management, 5(14), 5824-5832. doi:10.5897/AJBM11.076

Neelay, T. (2015). Global Teams That Work. Retrieved March 09, 2020, from Harvard Business Review Home: https://hbr.org/2015/10/global-teams-that-work

Paul, R., Drake, J., \& Liang, H. (2016). Global Virtual Team Performance: The Effect of Coordination Effectiveness, Trust, and Team Cohesio. IEEE TRANSACTIONS ON PROFESSIONAL COMMUNICATIO, 59(3), 186-202. doi:10.1109/TPC.2016.2583319

Pollitt, D. (2006). Finning finds a better way to manage. HUMAN RESOURCE MANAGEMENT INTERNATIONAL DIGEST, 4, 5-6. doi:DOI 10.1108/09670730610666283

Prasad , K., \& Akhilesh, K. (2002). Global virtual teams: what impacts their design and performance? Team Performance Management, 8(5/6), 102-112. doi:https://doi.org/10.1108/13527590210442212

Presbitero, A. (2019). Task performance in global virtual team. Personnel Review. doi:10.1108/PR-10-2018-0415

Saafein, O., \& Shaykhian, G. (2014). Factors affecting virtual team performance in telecommunication support environment Telematics and Informatics, 31(3), 459-462. doi:https://doi.org/10.1016/j.tele.2013.10.004

Siegel, N., \& Madni, A. (2019). Collaborative Creation of Engineering Artifacts by Geographically-Distributed Teams. Procedia Computer Science, 153, 250-259. doi:https://doi.org/10.1016/j.procs.2019.05.077

Sudhakar, G. (2012). A model of critical success factors for software projects. Journal of Enterprise Information Managemen, 25(6), 537-558. doi:https:// doi.org/10.1108/17410391211272829

Wei, L., Thurasamy, R., \& Popa, S. (2018). Managing virtual teams for open innovation in Global Business Services industry. Management Decision, 58(3), 1285-1305.

Zander, L., Mockaitis, A., \& Butler, C. (2012). Leading global teams§. Journal of World Business, 47, 592-603. doi:10.1016/j.jwb.2012.01.012

Zhang, Y., Sun, J., Yang, Z., \& Wang, Y. (2018). Mobile social media in inter-organizational projects: Aligning tool, task and team for virtual collaboration effectiveness. International Journal of Project management, 1096-1108. doi:https://doi.org/10.1016/j.ijproman.2018.09.003 